\title{
Spatiotemporal evolution of vegetative net primary productivity and its influencing factors in China's Yellow River Basin
}

\author{
Jiangsu $\mathrm{Li}^{1}$, Hongmei $\mathrm{CaO}^{2}$, Weihua $\mathrm{Li}^{2}$, Xiaoluan $\mathrm{Shi}^{2}$, yeqing han ${ }^{2}$, Xiaorui Wang ${ }^{2}$, and \\ Guanpeng Dong ${ }^{2}$ \\ ${ }^{1}$ Henan University - Minglun Campus \\ ${ }^{2}$ Henan University
}

October 5, 2021

\begin{abstract}
Ecosystem vulnerability in the Yellow River Basin (YRB) is a prominent concern. Exploration vegetative net primary productivity (NPP) serve as an important aspect of assessing and protecting ecosystem health. We used a range of spatial analysis techniques, residual trend analysis, and the cutting-edge computing-intensive variable importance decomposition method to explore spatiotemporal changes and influencing factors for vegetative NPP in the YRB from 2000-2015. The results found that NPP showed a fluctuating growth trend over time, ranging from 165.9-227.7 gC[?] m-2[?]a-1, as well as a clear negative southnorth spatial gradient. Significant spatial agglomeration pattern was observed, with Low-Low and High-High clusters being the dominated area classifications at both scales of grid cells, counties and cities in the study area. Foremost, we found that NPP was statistically significantly affected by both natural factors, including climate and topography, and human activities, whilst precipitation accounts for the most important factor, explaining roughly $42 \%$ of the variability in NPP on average. Although the impact of human activities on NPP was relatively low, human activities tended to promote NPP on average, mainly due to the implementation of the ecological restoration project in the region, such as the Forest Protection and Grain for Green Project. Overall, this study provides an improved technical framework for a comprehensive analysis of spatiotemporal pattern of vegetative NPP and its influencing factors at multiple-spatial scales.
\end{abstract}

\section{Hosted file}

manuscript.docx available at https://authorea.com/users/439616/articles/540508spatiotemporal-evolution-of-vegetative-net-primary-productivity-and-its-influencingfactors-in-china-s-yellow-river-basin 